\title{
Aging induced changes on NEXAFS fingerprints in individual combustion particles
}

\author{
V. Zelenay ${ }^{1}$, R. Mooser ${ }^{2, *}$, T. Tritscher ${ }^{3}$, A. Křepelová ${ }^{1}$, M. F. Heringa ${ }^{3}$, R. Chirico ${ }^{3,{ }^{* *}}$, A. S. H. Prévôt ${ }^{3}$, \\ E. Weingartner ${ }^{3}$, U. Baltensperger ${ }^{3}$, J. Dommen ${ }^{3}$, B. Watts ${ }^{4}$, J. Raabe ${ }^{4}$, T. Huthwelker ${ }^{4}$, and M. Ammann ${ }^{1}$ \\ ${ }^{1}$ Laboratory of Radiochemistry and Environmental Chemistry, Paul Scherrer Institut, 5232 Villigen PSI, Switzerland \\ ${ }^{2}$ EMPA, Swiss Federal Laboratories for Materials Research and Testing, Electronics/Metrology Laboratory, Ueberlandstrasse \\ 129, 8600 Dübendorf, Switzerland \\ ${ }^{3}$ Laboratory of Atmospheric Chemistry, Paul Scherrer Institut, 5232 Villigen PSI, Switzerland \\ ${ }^{4}$ Swiss Light Source, Paul Scherrer Institut, 5232 Villigen PSI, Switzerland \\ *now at: swissQuant Group AG, Kuttelgasse 7, 8001 Zurich, Switzerland \\ ** now at: Italian National Agency for New Technologies, Energy and Sustainable Economic Development (ENEA), \\ UTAPRAD-DIM, Via E. Fermi 45, 00044 Frascati, Italy
}

Received: 13 April 2011 - Published in Atmos. Chem. Phys. Discuss.: 11 May 2011

Revised: 20 October 2011 - Accepted: 14 November 2011 - Published: 24 November 2011

\begin{abstract}
Soot particles can significantly influence the Earth's climate by absorbing and scattering solar radiation as well as by acting as cloud condensation nuclei. However, despite their environmental (as well as economic and political) importance, the way these properties are affected by atmospheric processing of the combustion exhaust gases is still a subject of discussion. In this work, individual soot particles emitted from two different vehicles, a EURO 2 transporter, a EURO 3 passenger car, and a wood stove were investigated on a single-particle basis. The emitted exhaust, including the particulate and the gas phase, was processed in a smog chamber with artificial solar radiation. Single particle specimens of both unprocessed and aged soot were characterized using near edge X-ray absorption fine structure spectroscopy (NEXAFS) and scanning electron microscopy. Comparison of NEXAFS spectra from the unprocessed particles and those resulting from exhaust photooxidation in the chamber revealed changes in the carbon functional group content. For the wood stove emissions, these changes were minor, related to the relatively mild oxidation conditions. For the EURO 2 transporter emissions, the most apparent change was that of carboxylic carbon from oxidized organic compounds condensing on the primary soot particles. For the EURO 3 car emissions oxidation of primary soot particles upon photochemical aging has likely contributed as well. Overall,
\end{abstract}

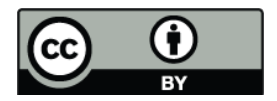

Correspondence to: M. Ammann (markus.ammann@psi.ch) the changes in the NEXAFS fingerprints were in qualitative agreement with data from an aerosol mass spectrometer. Furthermore, by taking full advantage of our in situ microreactor concept, we show that the soot particles from all three combustion sources changed their ability to take up water under humid conditions upon photochemical aging of the exhaust. Due to the selectivity and sensitivity of the NEXAFS technique for the water mass, also small amounts of water taken up into the internal voids of agglomerated particles could be detected. Because such small amounts of water uptake do not lead to measurable changes in particle diameter, it may remain beyond the limits of volume growth measurements, especially for larger agglomerated particles.

\section{Introduction}

The Earth's radiation balance is strongly affected by atmospheric aerosol particles, which absorb and scatter radiation (direct effect) or act as cloud condensation nuclei (indirect effect). In contrast to most aerosols, which cool the atmosphere by scattering radiation, soot particles, containing black carbon, warm the atmosphere by absorbing sunlight. After carbon dioxide $\mathrm{BC}$ is estimated to be the second strongest contributor to global warming (Jacobson, 2001), which effect depends heavily on the source of the soot particles and their atmospheric processing (i.e. their mixing state with transparent and hygroscopic aerosol components). Such processing can

Published by Copernicus Publications on behalf of the European Geosciences Union. 
change the light scattering and absorption properties (such as the single scattering albedo) of the soot particles (Adachi et al., 2010) as well as their lifetime in the atmosphere.

During atmospheric processing, the physical and chemical properties of soot particles are continuously altered through condensation and evaporation of various organic and inorganic compounds (Saathoff et al., 2003), coagulation with, e.g., sulfate particles (Worringen et al., 2008), oxidation (Petters et al., 2006), and restructuring (Abel et al., 2003). Such processing introduces large uncertainties in the quantitative evaluation of the radiative forcing of atmospheric soot particles (Moffet and Prather, 2009). Therefore, because the properties of atmospheric soot particles are highly variable and also strongly impact the Earth's radiation balance, experiments that further our understanding of these particles are essential to our understanding of, and ability to accurately model, the Earth's climate.

Coating experiments have been performed previously under defined laboratory conditions using, for example, carboxylic acids (Xue et al., 2009) or sulfuric acid (Zhang et al., 2008), in which changes in morphology were observed. Xue et al. (2009) reported that coating soot particles with glutaric and succinic acid increased both light scattering (up to 3.8 fold) and light absorption (less than 1.2 fold). While such laboratory experiments are useful in providing detailed information on the physical properties of processed particles, they do not represent the breadth of atmospheric processing that environmentally relevant soot particles are subject to, which is certainly much more complex (Robinson et al., 2007; Hamilton et al., 2004; Saathoff et al., 2003; Weingartner et al., 1997, 1995).

Atmospheric aging of soot has been assessed via aircraft (Schwarz et al., 2008) and balloon measurements (Renard et al., 2005) and indicate a fast mixing of soot particles with, for example, sulfate species (Johnson et al., 2005) and coating with secondary organic products (Moffet and Prather, 2009). This fast mixing impedes a direct comparison of fresh particles with their corresponding aged particles.

Filling the gap between laboratory and field studies, smog chamber experiments are ideally suited to following the evolution of soot particles as they are subject to direct oxidative processing and condensation of secondary organic material generated from the photo-oxidation of volatile organic compounds (VOC's) co-emitted with soot in combustion exhaust. Recently, such experiments were performed with exhaust from a diesel power generator (Sage et al., 2008; Weitkamp et al., 2007) as well as from biomass burning (Grieshop et al., 2009). This photochemical processing of exhaust is assumed to be the dominant soot aging mechanism, which is also directly related to the radiative properties of soot (Moffet and Prather, 2009).

This study deals with samples from a series of recent experiments at the Paul Scherrer Institute (PSI) smog chamber. Chirico et al. (2010) investigated directly emitted, primary organic aerosol (POA) and SOA formed by photooxidation of emissions from the same diesel passenger cars as used in this study. It was found that the formed SOA mass is significant: after five hours of aging about $80 \%$ of the total organic aerosol was on average secondary. These measurements were complemented by Tritscher et al. (2011b) who investigated the water uptake at sub-saturation and cloud condensation nuclei (CCN) activity of the fresh and photochemically aged soot from the same diesel passenger cars. Fresh diesel soot particles were found to be non-hygroscopic, i.e. they showed little or no interaction with water. No evidence was found that diesel soot is hydrophobic. Photochemical aging processes have various effects affecting the particles hygroscopic properties (e.g. condensation of oxidized organic compounds induces morphology changes by restructuring during water uptake). The primary emissions and secondary aerosol formation from two different log wood burners and a residential pellet burner under different burning condition are described by Heringa et al. (2011). SOA formation was found to be highly dependent on the type of stove and burning conditions. After five hours of aging, the average increase in OA concentration by SOA formation was found to be a factor of 4.1 for both log wood burners whereas no SOA formation was observed for the pellet burner during stable burning conditions.

In this study we focus on a few selected samples taken from the extended series of experiments just described. We focus on the analysis with scanning transmission X-ray microscopy (STXM), which allows retrieving morphological along with spectroscopic information from individual particles. In STXM, near edge X-ray absorption fine structure (NEXAFS) spectroscopy at the carbon edge allows obtaining spatially resolved carbon functional group composition of atmospheric particles (Russell et al., 2002). The novel aspect here is that this technique is applied to smog chamber samples enclosed within a microreactor to allow investigating water uptake to the particles at the oxygen edge in situ in parallel (Zelenay et al., 2011a; Huthwelker et al., 2010).

\section{Experimental section}

\subsection{Sample preparation}

All soot samples were sampled from the smog chamber (Paulsen et al., 2005) located at the Paul Scherrer Institute (PSI), Switzerland. A detailed description of the experiments is given by Chirico et al. (2010) and Heringa et al. (2011) and will be only briefly described here. The smog chamber, a Teflon bag with a volume of $27 \mathrm{~m}^{3}$, is temperature controlled within the range of $20-25^{\circ} \mathrm{C}$. Sunlight irradiation is simulated with four xenon arc lamps with a cutoff at $280 \mathrm{~nm}$. A photolysis rate of $J_{\mathrm{NO}_{2}}=0.11 \mathrm{~min}^{-1}$ is obtained. Different online particle analysis instruments were operated during the experiments, such as a scanning mobility particle sizer (SMPS), a volatility and hygroscopic tandem differential 
mobility analyzer (V/H-TDMA) (Tritscher et al., 2011a), and an Aerodyne high resolution time-of-flight aerosol mass spectrometer (AMS) (DeCarlo et al., 2006), to provide complementary data to compare with the single-particle measurements. Note that the AMS only measures compounds that evaporate at $600^{\circ} \mathrm{C}$ and hence, the refractory part of soot is not included in the AMS measurements. A Monitor Labs model ML9841A chemiluminescence $\mathrm{NO}_{\mathrm{x}}$ analyzer was used to measure $\mathrm{NO}$ and $\mathrm{NO}_{\mathrm{x}}\left(\mathrm{NO}, \mathrm{NO}_{2}\right)$, ozone was measured with an ozone analyzer Model 8810 (Monitor Labs Inc.), $\mathrm{CO}_{2}$ was measured with a differential, non-dispersive, infrared (NDIR) gas analyzer (LI-7000, LI-COR Biosciences) and, the gas-phase total hydrocarbon (THC) concentration was measured with a FID Model VE 7 (J.U.M. Engineering).

Emissions were sampled from two different vehicles, a EURO 2 Volkswagen Transporter TDI Syncro from December 2000 (with a mileage of $109000 \mathrm{~km}$, not equipped with emission abatement devices) and a EURO 3 Opel Astra 2.0 DTI passenger car from February 2002 (with a mileage of $45000 \mathrm{~km}$, equipped with a diesel oxidation catalyst (DOC)), as well as a log wood stove (Attika Avant). The vehicles were operated with low sulfur fuels $(10 \mathrm{ppm})$. Both cars were started with cold motors and were run idle during injection. In the wood stove experiments, the exhaust was injected into the chamber during the flaming phase. The wood used was beech that was stored in a dry place. The unfiltered exhaust gas of the two vehicles was diluted with particle-free, preheated $\left(150^{\circ} \mathrm{C}\right)$ air by a factor of seven immediately after emission. The exhaust was led through a heated $\left(150^{\circ} \mathrm{C}\right)$ injection system into the indoor smog chamber with a final dilution ratio of around 1:120 (Chirico et al., 2010). The transfer and dilution system for the exhaust from the wood stove was heated to $80^{\circ} \mathrm{C}$. The particle number concentration in the smog chamber ranged between 10000 20000 particles $\mathrm{cm}^{-3}$ and the primary particle mass concentration was between a few up to $50 \mu \mathrm{g} \mathrm{m}^{-3}$. After about one hour in the dark to allow for sampling of primary particles (see below), in case of the diesel exhaust experiments (not with the log wood burner), ozone was introduced into the smog chamber to oxidize $\mathrm{NO}$ to $\mathrm{NO}_{2}$. We presume that the primary fate of ozone was to titrate $\mathrm{NO}$ to $\mathrm{NO}_{2}$, which reacts much faster with ozone than alkenes and is in large excess. This has been confirmed by AMS measurements which did not show an increase in O:C ratios during this titration (Chirico et al., 2010). The levels of $\mathrm{NO}_{2}$ were $400-500 \mathrm{ppb}$ for the transporter experiments and 600-900 ppb for the passenger car experiments before switching on the lights. For the wood stove experiments, initial $\mathrm{NO}_{\mathrm{x}}$ levels were around $75 \mathrm{ppb}$. One hour after injection, the arc lamps in the smog chamber were turned on to begin irradiation. Once the lamps were switched on, propene (which is not a SOA precursor, Cocker et al., 2001) was added to increase the $\mathrm{VOC} / \mathrm{NO}_{\mathrm{x}}$ ratio and to raise the $\mathrm{OH}$ levels. Ozone was quickly produced and after about two hours, it reached a maximum concen- tration of $250-350 \mathrm{ppb}$ for the transporter experiments, 300 $400 \mathrm{ppb}$ for the passenger car experiments, and about $20 \mathrm{ppb}$ for the wood stove experiments. This was accompanied with the formation of SOA which leveled off after about $4-5 \mathrm{~h}$ (Chirico et al., 2010). Note that the STXM-NEXAFS measurements of the aged and fresh diesel combustion particles stem from processes conducted on different days but with identical processing and sampling conditions. For example, AMS measurements show a comparable increase in organic loading. Also note that the high resolution AMS data from the EURO 3 passenger car, i.e. O:C ratios, were taken from a separate, but identical, experiment run due to a software error during the experiments from which the STXM-NEXAFS samples were prepared.

Particles were sampled before and after aging of the diesel and wood combustion particles in the smog chamber. The unprocessed soot particles were sampled immediately after injection of the exhaust into the smog chamber, for diesel exhaust before addition of ozone. After $2 \mathrm{~h}$ of light induced aging, the first changes in hygroscopic properties of the soot particles were observed in the HTDMA, and the sampling of the aged soot particles was started.

For sampling of the primary soot particles, the soot particles were pumped out of the smog chamber, with a gas-flow of about $1.21 \mathrm{~min}^{-1}$, charged via a corona charger and deposited electrostatically $(0.8 \mathrm{kV})$ onto a silicon nitride membrane (Silson Ltd., Northampton, UK) during one hour. The membrane was glued (crystal bond, SPI suppliers, West Chester, USA) onto a small sample holder of the microreactor (see below). For the aged particles, the sampling was run during around four hours between two and six hours after the arc lamps were turned on in order to obtain a reasonable coverage of the membrane substrate.

Samples were stored at $-20^{\circ} \mathrm{C}$ until analysis.

\subsection{Microreactor}

Exposure of the sample to various relative humidity and temperature environments during X-ray measurements in the PolLux microscope was enabled by a custom microreactor (see Huthwelker et al. (2010) for a detailed description). Briefly, the microreactor consists of two parts: the sample substrate membrane, where the submicron particles are deposited and the body of the microreactor, which includes a capping membrane and a gas flow inlet and outlet. Fixing the two halves of the microreactor results in sandwiching the sample particles between two $50 \mathrm{~nm}$ thick silicon nitride membranes (with about $300 \mu \mathrm{m}$ separation) and thus within the enclosed volume of the microreactor. The membranes allow transmission of X-rays for STXM and NEXAFS measurements, while the microreactor gas inlet and outlet allows access to the enclosed volume for control of the sample environment.

The temperature of the microreactor is controlled by the combination of a heater and cooling via a copper braid 
attached to a liquid nitrogen dewar. The temperature during the X-ray measurements was set to $20^{\circ} \mathrm{C}$. A flow of 20 $50 \mathrm{ml} \mathrm{min}^{-1}$ of helium (at $150 \mathrm{mbar}$ ) was passed through the reactor during all measurements. The microscope chamber was evacuated to $10^{-2}$ mbar in order to reduce attenuation of the X-ray beam. A variable portion of the gas flow through the reactor can be, if required, humidified by passing the gas over a temperature controlled water bath. The relative humidity (RH) is measured using capacative sensors, operated at room temperature, at the exit line of the microscope chamber. A thermocouple mounted at the microreactor itself is used to enable corrections of the RH for the precise temperature in the microreactor. The RH can be adjusted from 0 to $95 \% \mathrm{RH}$.

Mounting the samples into the microreactor resulted first in about 30 min exposure to ambient air and about $1 \mathrm{~h}$ to the vacuum of the microscope, before the experimental pressure and temperature were adjusted.

\subsection{STXM-NEXAFS analysis}

The STXM and NEXAFS analyses were performed at the PolLux beamline (Raabe et al., 2008) of the Swiss Light Source (SLS) located at the Paul Scherrer Institute. Photons in the range of $200-1200 \mathrm{eV}$ are provided by this beamline with an energy resolution $(E / \Delta E)$ of about 3000 . The end station is equipped with a STXM operated with a spatial resolution of about $40 \mathrm{~nm}$ for the present experiments. The calibration of the spectra was performed by measuring the welldefined transitions of polystyrene spheres at the carbon edge (Dhez et al., 2003). All soot samples were measured in the microreactor (Zelenay et al., 2011a; Huthwelker et al., 2010).

To normalize the spectra and images, the Lambert-Beer law $\left(\mathrm{OD}=-\ln \left(I / I_{0}\right)=d \mu\right)$ was used, with OD being the optical density, $\mu$ the mass absorption coefficient, $d$ the thickness of the sample, $I$ the transmitted light intensity through the particle, and $I_{0}$ the incident light intensity (measured as the transmitted light intensity in a particle-free region nearby an individual particle).

All spectra were measured in the image stack mode, i.e. a series of images at closely spaced energy steps (Jacobsen et al., 2000). These image stacks were taken in energy steps of $0.15 \mathrm{eV}$ in the range of $284-292.5 \mathrm{eV}$ and in $0.3 \mathrm{eV}$ steps in the range of $280-284$ and $292.5-320 \mathrm{eV}$, respectively at the carbon K-edge (C K-edge). At the oxygen K-edge (O K-edge), step sizes of $0.2 \mathrm{eV}$ were used for $532-550 \mathrm{eV}$ and $0.5 \mathrm{eV}$ for $525-532$ and $550-560 \mathrm{eV}$, respectively. Absorption maps were converted from transmission images by applying the Lambert-Beer law. The chemical maps were generated from the absorption maps by subtracting the preedge absorption. The spectra were extracted using aXis2000 (Hitchcock, 2006).

\subsection{Scanning electron microscope}

The morphology of the particles was also analyzed using an SEM (Scanning Electron Microscope) (Zeiss Supra VP55) with a resolution of $1 \mathrm{~nm}$ operated at a voltage of $5 \mathrm{kV}$. The analysis was performed with the soot particles collected on the same sample holder, i.e. the same day and time, as for the microspectroscopy analysis. Size distributions were extracted from SEM images using the equivalent projected area diameter (Merkus, 2009). This distribution was obtained by calculating the projected surface area of the particles using threshold images. Qualitative observations and trends of particle sizes are discussed rather than quantitative values, although it was shown that for small agglomerates $(<100 \mathrm{~nm})$ this method gives reliable values (Ku and Maynard, 2005). Note that the sampling of the soot particles took about four hours so that no evolution of the particles sizes can be observed as with the SMPS and therefore averaged SMPS size distributions are shown.

Fractal dimensions were determined from the SEM images (Ku and Maynard, 2005) using the box counting method of ImageJ, a public domain image analysis program developed at the National Institutes of Health.

\subsection{HTDMA}

In this study, data from the H-part (hygroscopicity) of the V/H-TDMA are presented. Dry, monodispersed aerosols are selected in the first DMA. After exposure to high relative humidity $(\mathrm{RH})$ the aerosol particles are scanned with a second DMA coupled to a CPC (Condensation Particle Counter). All instrument parts are accommodated in a temperature controlled housing. The hygroscopic growth factor (GF) is defined as the wet particle diameter (here $\mathrm{RH}=95 \%$ ) normalized with the dry particle diameter $(\mathrm{RH}<10 \%)$.

The V/H-TDMA is equipped with a pre-humidification system in front of the first DMA. Particles are exposed to very high RH close to $100 \%$ before they are dried and size selected. Turning the pre-humidifier on allows restructuring of the fractal soot. The occurrence of restructuring can be identified when periods with and without pre-humidifier show a different GF.

The absolute GF uncertainty including the accuracy of the $\mathrm{RH}$ measurement is in the range of 0.05 (depending on the GF and RH). In this study the focus is on the temporal evolution at one constant high RH. For this the precision of the measurement is more important than the accuracy. Based on dry measurements, (so called D zero measurements to calibrate the sizing), the variation of the GF is smaller than $1 \%$. At the very low GF values (for soot) with little growth the overall uncertainty is about \pm 0.01 . Other effects like restructuring or swelling of the soot have a larger influence on the measurement. 


\section{Results and discussion}

\subsection{Particle morphology and size distribution}

Number size distributions of wood combustion particles are shown in Fig. 1. The blue bars represent the size distribution extracted from SEM images of fresh particles. For comparison, the SMPS size distribution is added to the plot as a black line. All size distributions are normalized by the total number of particles. The size distribution of the projected area diameter for aged particles is shown with red bars. Again, the SMPS size distribution plot is added, colored in grey. The SMPS data show that the mode of the electrical mobility diameter distribution of the fresh particles is $190 \mathrm{~nm}$. The evaluation of the size distribution using SEM images shows that most particles have a size between 60 and $250 \mathrm{~nm}$ with a tail reaching up to about $700 \mathrm{~nm}$. The size distribution of the aged particles is broadly similar to that of the primary particles, but shows a tail reaching towards larger diameters $(1 \mu \mathrm{m})$. This is also reflected in the SMPS data, which show a shift of the mode diameter to around $240 \mathrm{~nm}$. Obviously, the relative amount of small particles is somewhat overestimated with the SEM images. This may be related to the fact that the soot particles were sampled by electrostatic deposition, which prefers to some extent the smaller particle sizes. In general, the SEM sizes may be slightly underestimated due to evaporative losses during analysis. Also note that two different kinds of calculations were used to obtain the size data. We used 2-D microscopic images to obtain a diameter (as explained in the experimental section), while the SMPS measures the electrical mobility diameter, see also $\mathrm{Ku}$ and Maynard (2005).

Figure 1 illustrates SEM images of single wood combustion particles. The left SEM image illustrates two fresh wood combustion particles, the right one an aged particle. A typical wood combustion particle consists of primary spherical particles in the range of 40 to $50 \mathrm{~nm}$, which agglomerate to large structures (Vernooij et al., 2009; Kocbach et al., 2005). Because the exhaust of the wood burning was sampled during the flaming phase, it makes sense that no tar balls were observed here (Vernooij et al., 2009).

The aged wood combustion particles show very often a partly collapsed chain-like structure, especially in large particles $(>800 \mathrm{~nm})$ as shown in Fig. 1, but the calculated fractal dimensions remains unchanged within error. A fractal dimension of $1.81( \pm 0.08)$ was measured for fresh particles and $1.84( \pm 0.06)$ for aged particles. It should be noted, however, that this result may be biased by the fact that semivolatile secondary organic aerosol may have evaporated in the high vacuum of the SEM, such that the actual fractal dimension of the aged particles may be higher.

Figure 2 illustrates the different particle number size distributions from the EURO 2 transporter exhaust. The color code is the same as described for Fig. 1. The evaluation of the SEM images from fresh particles shows that most particle

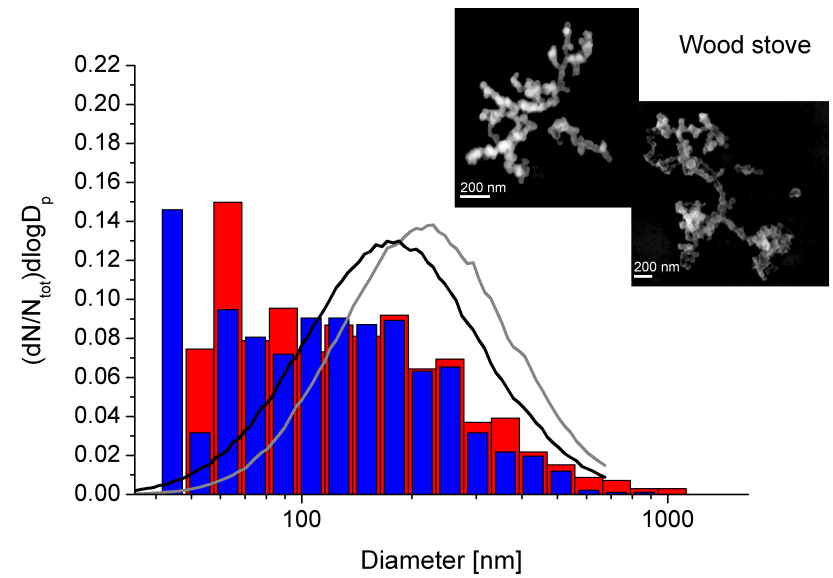

Fig. 1. Size distributions extracted from the SEM images using the equivalent projected area diameter (bars) and the electrical mobility diameter measured with the SMPS (lines) of the fresh (blue and black) and aged (red and grey) wood stove combustion particles, respectively. The insets are SEM images of a fresh (left) and aged (right) soot particle having projected area sizes of: $205 \mathrm{~nm}$ for the small particle and $480 \mathrm{~nm}$ for the large particle on the left, and $1 \mu \mathrm{m}$ for the aged wood particle on the right.

sizes are found between $40 \mathrm{~nm}$ and $200 \mathrm{~nm}$, also here a small tailing to around $250 \mathrm{~nm}$ is observed. The aged particles show a size distribution up to $600 \mathrm{~nm}$. The SMPS measurements show an increase in the mode diameter from $85 \mathrm{~nm}$ for fresh particles to $125 \mathrm{~nm}$ upon aging in the smog chamber. Again, SEM images of single particles are depicted in Fig. 2. Consistent with other authors (Adachi et al., 2007; van Poppel et al., 2005; Kis et al., 2006), primary particles are found with a size of about $30-40 \mathrm{~nm}$ aggregated in chains. Inspection by eye does not reveal changes in aggregation of the particles, which is supported by the evaluation of the fractal dimension revealing $1.84( \pm 0.03)$ for fresh and $1.85( \pm 0.05)$ for processed particles, respectively.

Figure 3 shows the particle size distributions of the EURO 3 passenger car exhaust. The symbols and colors are explained in conjunction with Fig. 1. While the fresh particles have sizes between 50 and $200 \mathrm{~nm}$, comparable to the particles emitted from the EURO 2 transporter, the aged particles show sizes around $100 \mathrm{~nm}$ with a second mode at around $400 \mathrm{~nm}$. In the SMPS such a second mode is not apparent likely because the SMPS only measured up to an electrical mobility diameter of $680 \mathrm{~nm}$. The SMPS reveals a mode diameter of $80 \mathrm{~nm}$ for fresh and $145 \mathrm{~nm}$ for aged particles, respectively. Whether the second mode at large diameters as seen by SEM is formed on the substrate or other processes remains open. SEM images of a single particle each are added in the figure. Again, the primary particles of fresh and aged soot show the typical size of about $30-40 \mathrm{~nm}$ as observed for the transporter. Also in this case, no changes of the aggregation of the soot chains upon soot aging were observed, which 


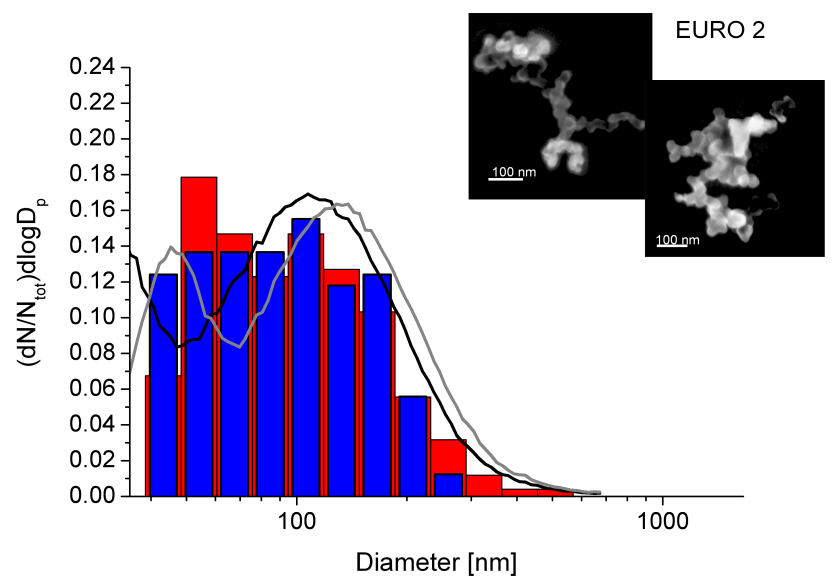

Fig. 2. Size distribution of the particles emitted from the EURO 2 transporter, the red and blue bars represent size distributions from fresh and aged soot particles, respectively. The black and grey lines represent the SMPS size distribution from fresh and aged particles, respectively. The diameters of the particles in the SEM images are: $250 \mathrm{~nm}$ for the fresh particle (left) and $300 \mathrm{~nm}$ for the aged particle (right).

is supported by the fractal dimensions being $1.87( \pm 0.03)$ for fresh soot particles and $1.87( \pm 0.03)$ for aged particles. The morphology of soot particles stemming from the cars do not seem to be influenced significantly by aging.

In summary, the equivalent projected area diameter shows, in general, a comparable particle size distribution as measured by the SMPS, and the size increases were also reproduced. The systematic differences between the two methods may be related to the preference of the electrostatic sampling method for the smaller particle sizes and to coagulation on the substrate. These results confirm that the $150-200 \mathrm{~nm}$ diameter particles that were chosen for STXM analysis were representative of the total particle populations. Investigating size dependent chemical composition was not the scope of the analysis presented below.

\subsection{STXM-NEXAFS characterization}

Figure 4 illustrates STXM absorption maps of soot particles from the wood stove (left panel), from the EURO 2 transporter (middle panel) and from the EURO 3 passenger car (right panel), measured at $320 \mathrm{eV}$. Absorption at this energy is dominated by carbon, independent of its chemical form. These images also demonstrate the agglomerate structure as evident from the SEM analysis presented above, but with poorer spatial resolution. Absorption images of individual particles at different energies were used to extract absorption spectra and O:C ratios as presented below. We did not attempt to look at chemical inhomogeneity within individual particles. Error bars in average spectral data presented below are dominated by particle to particle variation.

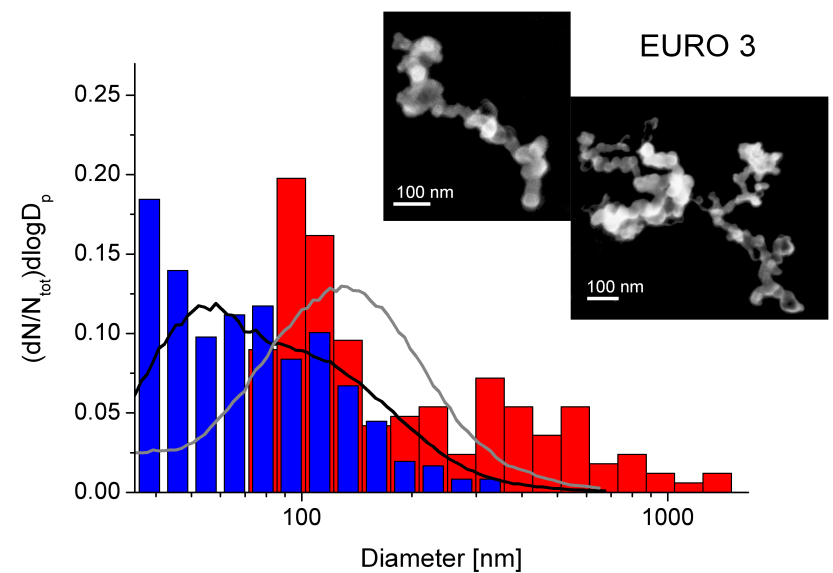

Fig. 3. Size distributions measured using SEM images and the SMPS shown in bars and lines. Blue and red bars, black and grey lines illustrate the fresh and aged particles. The projected area diameter of the illustrated soot particles are $220 \mathrm{~nm}$ for the fresh particle (left) and $390 \mathrm{~nm}$ for the aged soot particle (right).

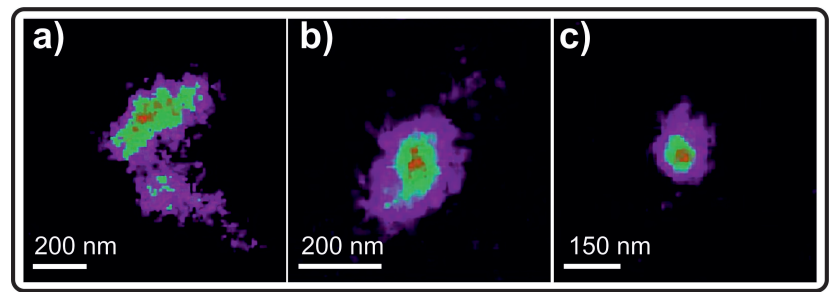

Fig. 4. STXM absorption images, measured at $320 \mathrm{eV}$, of aged soot particles emitted from (a) the Attika wood stove with an equivalent projected area diameter of around $500 \mathrm{~nm}$, (b) the EURO 2 transporter having a diameter of $260 \mathrm{~nm}$ and (c) the EURO 3 passenger car with a diameter of about $170 \mathrm{~nm}$. The $\mathrm{OD}$ values scale up to 0.5 .

NEXAFS spectra from the single particles are shown in Fig. 5. Each spectrum represents the average of several individual particles, using the image-stacks described in the experimental section. Specific chemical species were quantified from the spectra by fitting with Gaussian functions representing characteristic near-edge resonances (Outka and Stohr, 1988), using resonance positions adopted from Hopkins et al. (2007). The peak energies were fixed at the $\mathrm{C} 1 \mathrm{~s} \rightarrow$ $\pi^{\star}$ transition of aromatic carbon in benzoquinone (quinoneC, $284.2 \mathrm{eV}$ ), of unsaturated carbon (aromatic-C, $285.2 \mathrm{eV}$ ), of phenolic or ketone carbon (phenol-C, $286.7 \mathrm{eV}$ ), of carboxylic carbon (carboxyl-C, $288.3 \mathrm{eV}$ ), of carbonyl carbon (carbonyl-C, $290.5 \mathrm{eV}$ ) and at the $\mathrm{C} 1 \mathrm{~s} \rightarrow \sigma^{\star}$ transitions of aliphatic carbon (aliphatic-C, $287.4 \mathrm{eV}$ ), which overlaps with the $\mathrm{C} 1 \mathrm{~s} \rightarrow \pi^{\star}$ transition of aromatic carbonyl groups, of Oalkylic carbon $(289.5 \mathrm{eV})$, and of aliphatic/aromatic carbon (aliphatic/aromatic-C, $292 \mathrm{eV}$ ). An example of such a fit is illustrated in Fig. 6 and shows the NEXAFS spectrum of an 


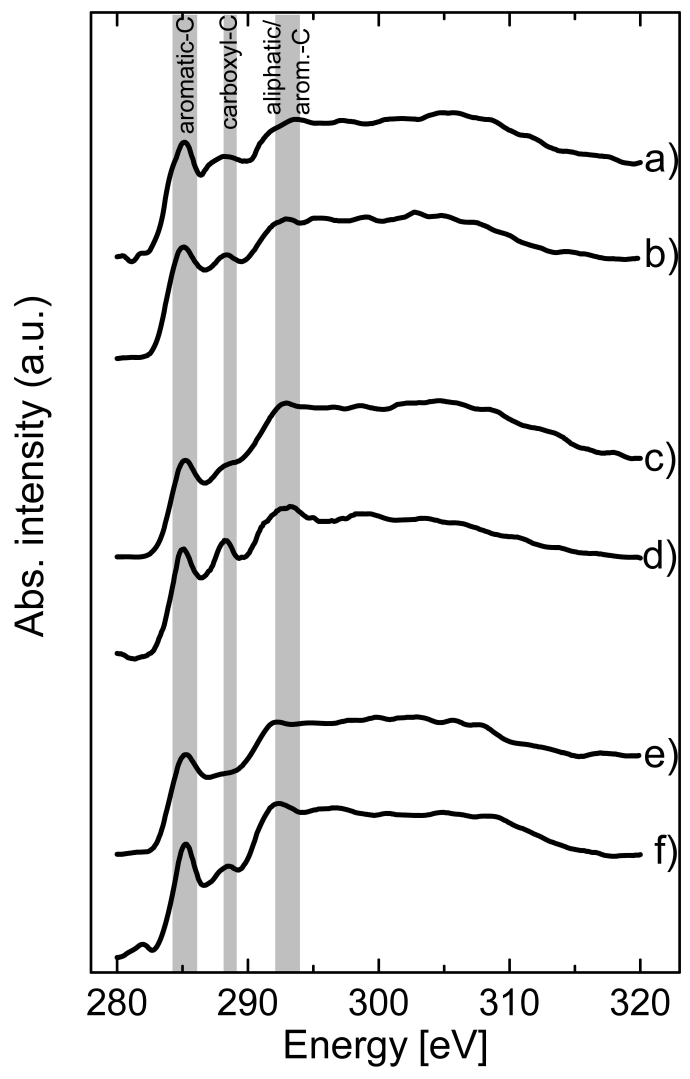

Fig. 5. Averaged C K-edge NEXAFS spectra of (a) fresh soot emitted from the Attika wood stove (12), (b) the corresponding aged soot (19), (c) unprocessed soot particles from the EURO 2 transporter (7), (d) aged soot particles from the transporter (12), (e) unprocessed soot stemming from the EURO 3 passenger car (5), (f) aged soot from the passenger car (9), values in brackets define the number of spectra used for averaging.

aged wood combustion particle. A broad absorption feature at $305 \mathrm{eV}$ indicates a high $\pi$-bond conjugation (Diaz et al., 2007). Due to the inhomogeneous composition of soot small shifts in the maxima of the transition energies of the single particles are expected. Only the maxima of the peak intensities at $285.3,288.3$ and $292 \mathrm{eV}$ could be unambiguously distinguished for the fit of the spectrum. The maximum of the unsaturated carbon peak shifted from 285.1 to $285.3 \mathrm{eV}$, while the transition of the carboxyl carbon was assigned between $288.3-288.4 \mathrm{eV}$. The aliphatic/aromatic-C peak shifted from 292 to $292.2 \mathrm{eV}$. Note that these energy shifts are close to the energy resolution of the beamline. All other maxima were fixed at the aforementioned values during the fitting procedure. The peak fitting results are presented in Fig. 7. A significant uncertainty especially for the fits at $292 \mathrm{eV}$ is introduced by the assumption used to represent the ionization edge. The slope and height of the arctangent function normally used are unknown for the single particles. It is reasonable to assume a distribution of ionization energies in view

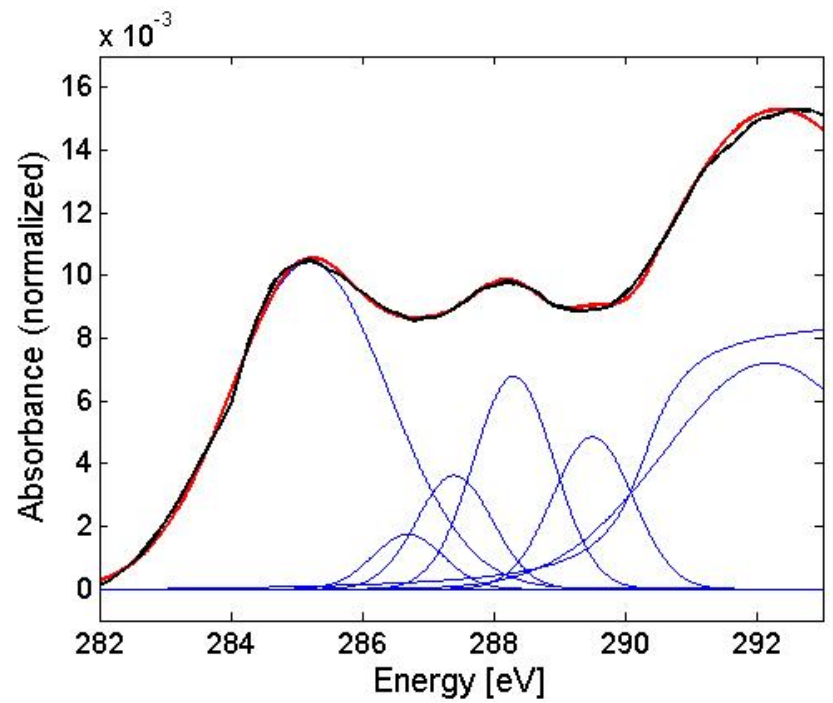

Fig. 6. Example of a gauss fitting of a NEXAFS spectrum for wood combustion particles, the black solid line represents the original spectrum, the red one represents the fit. The maxima of the Gaussian peaks were placed at $284.2 \mathrm{eV}$ (quinone-C), 285.2 eV (aromatic-C), $286.7 \mathrm{eV}$ (phenolC), $287.4 \mathrm{eV}$ (aliphatic-C), $288.3 \mathrm{eV}$ (carboxyl-C), $289.5 \mathrm{eV}$ (Oalkyl-C), $290.5 \mathrm{eV}$ (carbonyl-C) and at $292 \mathrm{eV}$ (aliphatic-C).

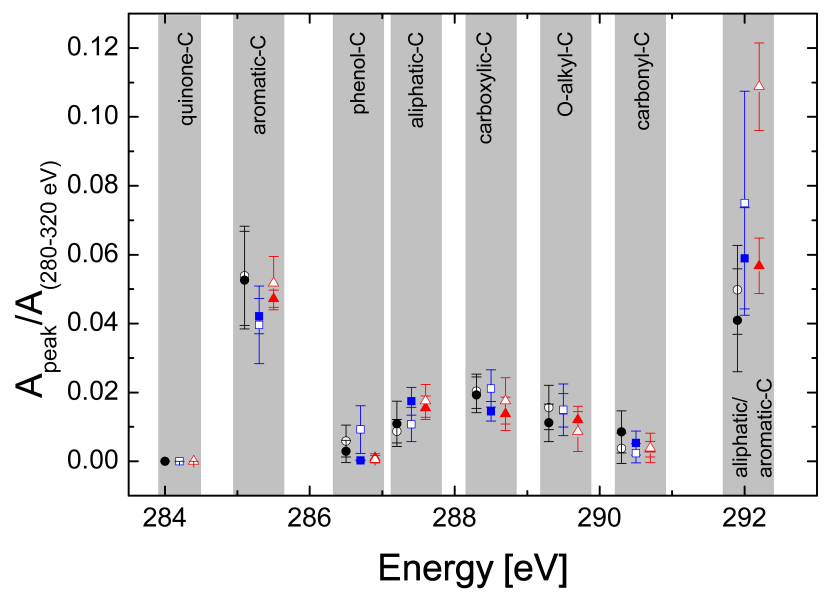

Fig. 7. Representation of the averaged single contributions of the fitted gauss integrals with their standard deviations. All spectra were normalized by the integral of the carbon edge spectrum from 280 $320 \mathrm{eV}$. The black circles illustrate the soot particles from the wood stove, the blue squares the EURO 2 transporter soot particles and the red triangles the EURO 3 passenger car soot particles. The solid and open symbols represent the unprocessed and aged soot particles, respectively.

of the broad variety of carbon species present in soot (Outka and Stohr, 1988). The spectra were normalized to the area of the whole spectrum. 
Spectrum a) in Fig. 5 shows the averaged NEXAFS spectrum of fresh wood combustion particles. A distinct absorption at $285 \mathrm{eV}$ and at $292 \mathrm{eV}$ suggests a high aromatic content in the combustion particles. Further, an absorption in the carboxyl-C region $(288.5 \mathrm{eV})$ can be observed, which suggests also a high content in carboxyl-C. The Gaussian fit analysis shown in Fig. 7 demonstrates that the absorption from quinone-C $(284.2 \mathrm{eV})$ is absent. Furthermore, the analysis shows that fresh wood combustion particles exhibit small absorption at the phenolic-C energy but high transition intensity from carbonyl-C. However, also alkyl- and O-alkyl$\mathrm{C}$ are involved in the absorption spectrum. Potassium salts are expected to be associated with wood combustion particles, but remain at or below the percent level of total carbon (McDonald et al., 2000; Fine et al., 2001). The characteristic potassium double peak near $300 \mathrm{eV}$ remained thus undetected in the C-edge spectra.

Spectrum b) in Fig. 5 shows the averaged spectrum of the corresponding aged particles. Again, high absorption intensities are found in the aromatic region (285 and $292 \mathrm{eV}$ ), and in the carboxyl-C region $(288.5 \mathrm{eV})$. These observations are confirmed by the Gaussian fitting results. While phenol and O-alkyl content slightly increased upon processing, a decrease in carbonyl- and aliphatic-C can be observed. The absorption intensity at $292 \mathrm{eV}$ shows a slight increase. The ratio of the peak heights of the averaged spectra (Fig. 5) at 285 divided by the peak height at $292 \mathrm{eV}$ is used to quantify the degree of graphitization in carbonaceous materials (di Stasio and Braun, 2006). This ratio shows a decreasing trend from 0.84 to 0.80 upon aging indicating an increase in alkyl-C and decrease in aromatic-C, which includes also unsaturated carbon. Note that the sensitivity of the intensity at $292 \mathrm{eV}$ to the representation of the ionization edge (see also error bars in fit results at this energy) makes this analysis quite uncertain, even though the changes at $285 \mathrm{eV}$ are significant. AMS measurements performed by Heringa et al. (2011) showed a slight increase at $\mathrm{m} / \mathrm{z} 44$, which is attributed to carboxylic groups $\left(\mathrm{CO}_{2}^{+}\right)$in mono- and diacids (Duplissy et al., 2011; Alfarra et al., 2007), from 10.1 to $10.3 \%$. The fit over 5 hours results in a $0.12( \pm 0.30)$ increase $(95 \%$ confidence interval), consistent with the trend of the relative increase of carboxylic groups as apparent from the NEXAFS spectra. The AMS data also show that photo-oxidation increases the total organic carbon by a factor of 3 compared to primary particles. O:C ratios can be calculated by comparing the preedge $(280 \mathrm{eV})$ and the post-edge absorption $(320 \mathrm{eV})$ with the attenuation coefficients taken from Chantler (Chantler, 1995) and assuming only carbon and oxygen being present in the soot particles. A ratio (and corresponding standard deviation) of $0.30( \pm 0.22)$ for fresh and $0.35( \pm 0.30)$ for aged wood combustion particles is found indicating only little enrichment of oxygen relative to carbon in the processed particles. Comparable values are revealed from AMS data, which showed a ratio of $0.35( \pm 0.11)$ for fresh wood combustion particles and a ratio of $0.40( \pm 0.12)$ for processed particles. Note that only compounds that evaporate at $600^{\circ} \mathrm{C}$ are measured with the AMS. In summary for the wood combustion particles, the SOA material that has mostly resulted from oxidation in the gas phase and condensation to the particles has slightly more carboxylic groups and less aromatic carbon than organic material associated with the primary particles. While the $\mathrm{OH}$ budget cannot be assessed in detail for these experiments, the mild photochemical conditions, represented by light intensity corresponding to middle European winter afternoon, have caused the relatively small changes to carbon oxidation state in spite of the substantial particulate mass changes.

Spectrum c) in Fig. 5 shows an averaged spectrum of the fresh soot particles emitted from the EURO 2 transporter. A high absorption intensity at $285.2 \mathrm{eV}$ can be observed. The steep increase at $292 \mathrm{eV}$ and the absorption at $305 \mathrm{eV}$ show the high degree of conjugation from large PAHs, graphene and graphite type moieties. A weak absorption is found at around $288.3 \mathrm{eV}$ that which indicates a low degree of oxidation of the soot particles. The fitting analysis (Fig. 7) shows strong particle to particle variability in the absorption intensities of the aromatic carbon, both at $285.2 \mathrm{eV}$ and $292 \mathrm{eV}$. Again, the fitting analysis shows no evidence for phenol- or quinone-C absorption.

The spectrum of the aged particles from the EURO 2 transporter depicted in trace d of Fig. 5 show a slightly higher aromatic content. The ratio of the peak height at 285 divided by the peak height at $292 \mathrm{eV}$ increases upon aging, from 0.63 to 0.72 , indicating a decrease in alkyl-C, which is consistent with the AMS measurements (Chirico et al., 2010), and increase in unsaturated carbon, respectively. The carboxylic-C at $288.3 \mathrm{eV}$ from the aged EURO 2 transporter particles shows the highest absorption intensity of all investigated particles. The fitting analysis confirms these observations. The AMS data support the analysis and show an increase of the mass fraction $\mathrm{m} / \mathrm{z}, 44$ (Chirico et al., 2010). The fresh soot particles showed a carboxylic carbon content of about $2.5 \%$ of the total mass while in the aged particles a fraction of $5.4 \%$ was reported. The organic mass was shown to increase by a factor of around 4 in this experiment due to formation of SOA. Therefore, the increase in carboxylic-C in the NEXAFS spectra is most likely due to secondary organic compounds condensed from the gas phase. The $\mathrm{O}: \mathrm{C}$ ratios as derived from the $\mathrm{C}$ edge pre- and postedge absorptions were $0.16( \pm 0.39)$ for fresh and $0.32( \pm 0.27)$ for the aged EURO 2 particles. This is consistent with the addition of carboxyl-C and phenol-C in the particles as observed in the resonant features at the absorption edge itself. From the AMS data, O:C ratios of $0.1( \pm 0.03)$ for fresh and $0.34( \pm 0.11)$ for aged particles were reported (Chirico et al., 2010). As demonstrated by both the NEXAFS and AMS proxies for carboxylic acids, the primary EURO 2 transporter emissions have lower carboxylic acid fractions than those from the wood stove. Therefore, condensation of more oxidized material in both cases leads to larger relative changes for the EURO 2 diesel exhaust 
particles in terms of carboxylic acids. Besides the highly oxidized carbon compounds that condense on the EURO 2 soot particles, the aged particles show a high content of unsaturated and phenolic carbon which might also stem from oligomerization and aldol type condensation reactions. Aldol condensation requires acidic conditions, but also ammonium salts were shown to be efficient catalysts for similar aggregation reactions in atmospheric aerosols (Nozière et al., 2010). As described in the experimental part, a measurable, but small increase in sulfate, but unchanged and very low ammonium content leaves room for excess acidity, which, along with a relative humidity of $50 \%$, could provide a substrate for such particle phase reactions. Another process may also be that the light absorbing portions of soot may initiate condensed phase reactions (Zelenay et al., 2011b). Thus, particulate phase aging processes may be the result of both the condensation of gas phase species and chemical processes initiated within the condensed phase. However, we emphasize that the results available do not provide the means to differentiate the relative importance of the two.

The averaged spectrum (Fig. 5e) of the unprocessed soot of the EURO 3 passenger car shows also a high absorption of the aromatic carbon at 285.2, as well as at 292 and $305 \mathrm{eV}$. Again, this points to a high graphitic content in these particles (Diaz et al., 2007). Similar to the EURO 2 transporter emissions, the absorption intensity of the carboxyl-C is low and no phenol-C nor quinone-C absorption is observed. This is confirmed by the fitting analysis (Fig. 7). The corresponding spectrum of the aged particles is shown in Fig. 5f). An increase in the absorption intensity of the carboxyl-C region is observed, which is also supported by the AMS measurements revealing an increase in the carboxyl content from $1.6 \%$ in fresh soot particles to a content of $3.2 \%$ in aged particles (Chirico et al., 2010). This increase was accompanied by a comparably small increase in the aromatic-C at 285.2 and $292 \mathrm{eV}$ in the NEXAFS spectra. The Gaussian fitting analysis, displayed in Fig. 7, confirms the aforementioned changes. Note that the Gaussian fitting possibly exaggerates the absorption intensity at $292 \mathrm{eV}$, due to the uncertainty of placing the ionization edge properly, as mentioned above. The ratio of the peak height at 285 divided by the peak height at $292 \mathrm{eV}$ shows a decrease from 0.76 to 0.72 upon aging, indicating an increase in alkyl-carbon groups. Additionally, it shows that no phenol- $\mathrm{C}$ evolved during the processing in the smog chamber, in difference to the EURO 2 transporter case. The O:C ratios derived here are $0.12( \pm 0.13)$ for the fresh and $0.25( \pm 0.18)$ for aged particles, which are again consistent with the AMS data reported by (Chirico et al., 2010) ( 0.1 for fresh and 0.22 for processed particles). In this case, the AMS observed only a slight increase in organic mass by around $25 \%$ from the starting concentration. Therefore, the increase in carboxylic-C might also stem from primary particle oxidation and not necessarily only from the oxidized organic compounds that condensed on the soot particle. The increase of the alkyl-C must have originated from organic compounds condensed from the gas phase as there is no other source available that could reasonably explain this increase.

In summary for the diesel exhaust particles, the apparent change in the NEXAFS fingerprints upon aging is the increase in carboxylic acid content. For the EURO 2 transporter emissions the aged particles are dominated by secondary organic material, and thus the carboxylic acid content is mostly representative for that secondary material. For the EURO 3 passenger car exhaust the increase in carboxylic acid may also be associated with oxidation of primary organic material, since the mass of secondary organic compounds remained small (Chirico et al., 2010). A remaining caveat in this analysis may be that some semivolatile material may have evaporated before and during analysis by STXM, even though the reasonable consistency of O:C ratios between AMS and X-ray absorption data indicate that this would at least not have affected the assessment of oxidized functional groups.

\subsection{Water uptake in soot particles}

The water uptake behavior of the different soot particles was investigated via NEXAFS spectra measured at the oxygen edge and images measured at the oxygen edge and carbon pre-edge. The carbon NEXAFS analysis revealed a relatively low O:C ratio in most of the single soot particles. A NEXAFS analysis at the oxygen edge was impeded by the low oxygen content in the dry particles which lead to low absorption and insufficient statistics for clear spectra. The $\mathrm{O}$ $\mathrm{K}$-edge spectra reported below were measured for the aged wood stove sample at $0 \%$ and $90 \%$ RH and the fresh wood combustion particles at $90 \% \mathrm{RH}$ as well as for the aged soot from the EURO 2 transporter at $90 \% \mathrm{RH}$. The spectra at the oxygen edge were only obtained from 2-3 particles, selected for having sufficient absorption at the oxygen edge and therefore may not be entirely representative.

Spectrum a) in Fig. 8 shows the oxygen spectrum of unprocessed wood stove soot measured at $90 \% \mathrm{RH}$. The main absorption is found at $538.2 \mathrm{eV}$, which is attributed to the transition of ketone-, carboxyl- or alcohol-O. A second absorption is found at around $532 \mathrm{eV}$. This absorption intensity is assigned to the $\mathrm{O} 1 \mathrm{~s} \rightarrow \pi^{\star}$ transition of carboxyl- and ketone-O (Hopkins et al., 2007). Spectrum b) is from the aged soot sample from the wood stove at $0 \% \mathrm{RH}$. It also displays strong absorption peaks centered at $532 \mathrm{eV}$ and $539 \mathrm{eV}$, which are attributed to the transitions of the aforementioned oxygenic functional groups. Spectrum c) is also from an aged wood combustion particle as b) but measured at $90 \%$ RH. This spectrum strongly resembles that of liquid water (Tzvetkov et al., 2008; Cavalleri et al., 2002; Wernet et al., 2004), displayed as spectrum (e) in the Figure. Since water does not absorb at $532 \mathrm{eV}$, this peak is strongly diminished and indicates the dilution of the organic compounds by water, which apparently dominates the absorption at the oxygen edge under humid conditions. Figure $8 \mathrm{~d}$ shows the 


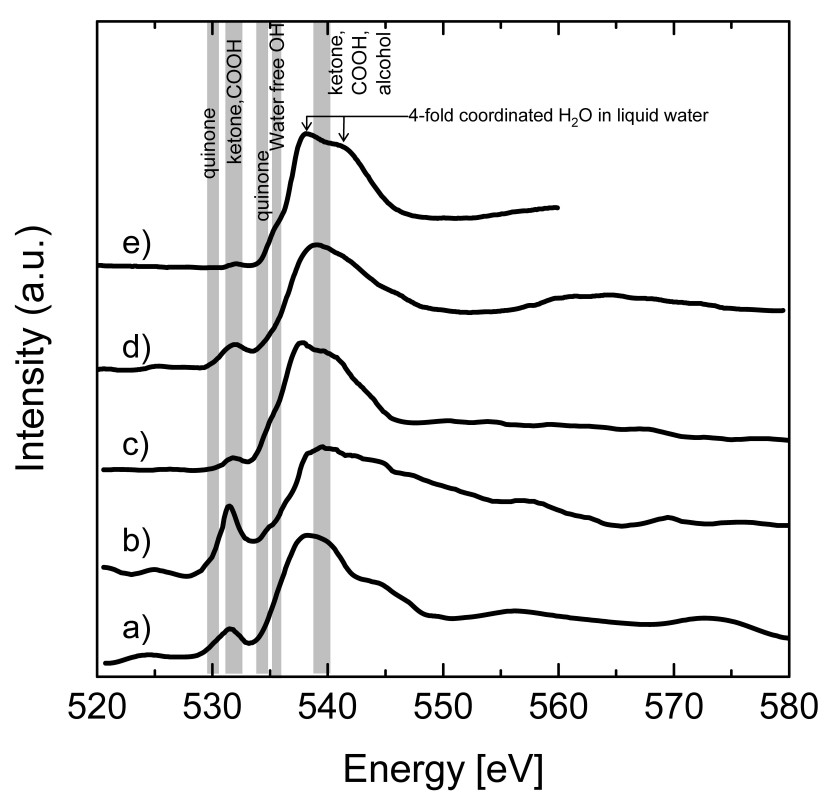

Fig. 8. O K-edge NEXAFS spectra of (a) fresh soot particles from the wood stove measured at $90 \% \mathrm{RH}$, (b) aged soot from wood stove at $0 \% \mathrm{RH}$, (c) same particles as in (b) at $90 \% \mathrm{RH}$, (d) aged soot from the EURO 2 transporter at $90 \% \mathrm{RH}$, (e) liquid water taken from Tzvetkov et al. (2008). The spectra are normalized to the highest absorption intensity.

spectrum of the EURO 2 transporter exhaust particles, measured at $90 \% \mathrm{RH}$. The main absorption is found at $539 \mathrm{eV}$ with a smaller transition at $532 \mathrm{eV}$. The position of the main edge and the absence of a shoulder at $535 \mathrm{eV}$ indicate only a small contribution from water. The main edge is similar to the dry spectrum of particles from wood combustion.

Detection of water by NEXAFS is related to changes in absorption at the oxygen edge (or also carbon edge, as discussed below). Because we always consider normalized spectra, detection of water uptake to the particles remains linked to the total amount of oxygen in the particles. For humidified aged wood combustion particles, the amount of water-oxygen is larger than the amount of oxygen associated with the dry particles. In contrast, for the EURO 2 transporter diesel exhaust particles, the amount of water taken up remained small in comparison to the amount of oxygen in dry soot, indicating incomplete solvation of oxygenated material or functional groups. This way of interpretation of water uptake from the NEXAFS data should be kept in mind, when images are discussed below and compared to other data.

Images of individual soot particles were recorded at different RH in order to quantify the water uptake. As described above, the oxygen content was too low in certain soot particles, so that measurements at the oxygen edge were not possible in many cases. Therefore, the changes in the preedge region at the carbon edge were used to map the water uptake in particles with low oxygen content. The side effect of this approach is that the particles are detected using the X-ray absorption at the carbon edge and hence there is no pre-selection bias towards oxygen content of the dry particles. Nevertheless, note that the contribution of oxygen to the absorption at the carbon pre-edge remains small and therefore also the differences in absorption intensity at various RH. Therefore, criteria for detecting water uptake were defined, which include (1) a consistent change of the absorption intensity of the single particles with varying $\mathrm{RH}$; this means that the absorption increased simultaneously with $\mathrm{RH}$ and vice versa, and (2) larger than $10 \%$ difference in the absorption intensities of the single particle upon water uptake. Whether absorption changes are observed at the $\mathrm{C}$ or $\mathrm{O}$ edge has no influence on the discussion above that this method is sensitive to the relative increase in oxygen. No changes in the soot morphology were observed upon water uptake. The expected small changes upon restructuring are beyond the spatial resolving power of STXM as operated in the present experiments. The time steps in between the different RH settings were chosen to be at least $30 \mathrm{~min}$ before the measurements were continued in order to allow the water uptake to reach equilibrium.

Figure 9 shows the chemical map of one soot structure from out of aged wood combustion particles at the oxygen edge at $0 \%, 70 \%, 93 \%$ and returning to $0 \% \mathrm{RH}$ again. At $70 \% \mathrm{RH}$ a first small change can be observed, which is manifested more clearly at $93 \% \mathrm{RH}$. A very high uptake can be observed in some parts of the soot structure, which are colored in green and red. Here, an averaged water column of about $40 \mathrm{~nm}$ per image pixel is observed (assuming a density of $1 \mathrm{~g} \mathrm{~cm}^{-3}$ ). In the other regions of the particle, an average water column of around $10 \mathrm{~nm}$ is observed. Returning again to $0 \% \mathrm{RH}$, the absorption decreases to the initial values. From 16 investigated particles/structures, 11 were found to take up water. The unprocessed wood particles were also investigated, but the absorption intensity changes were inconsistent during changes of $\mathrm{RH}$ and further evaluation of these data has been omitted, as obviously water uptake was below the detection limits as defined above. The HTDMA measurements, shown in Fig. 10, indicate a restructuring of the soot particles after exposure to $95 \% \mathrm{RH}$. A GF of 0.95 was measured after six hours. Although a strong restructuring was observed indicating a compaction of the aged soot particles under high RH, after pre-humidification a GF of only 1.03 was measured (Fig. 10), indicating only little water uptake. Note that the HTDMA measures the change in electrical mobility diameter (equivalent diameter calculated from the mobility of the charged particles in the carrier gas). For compact particles, the growth can be directly converted into a change in volume due to water uptake. For agglomerate particles (even in absence of restructuration), quantification of the volume of water taken up is difficult. In contrast, the $\mathrm{X}$-ray absorption measurements quantify the water uptake in terms of mass, which is a better indicator of water uptake in these particles. As noted already above, due to the relatively 


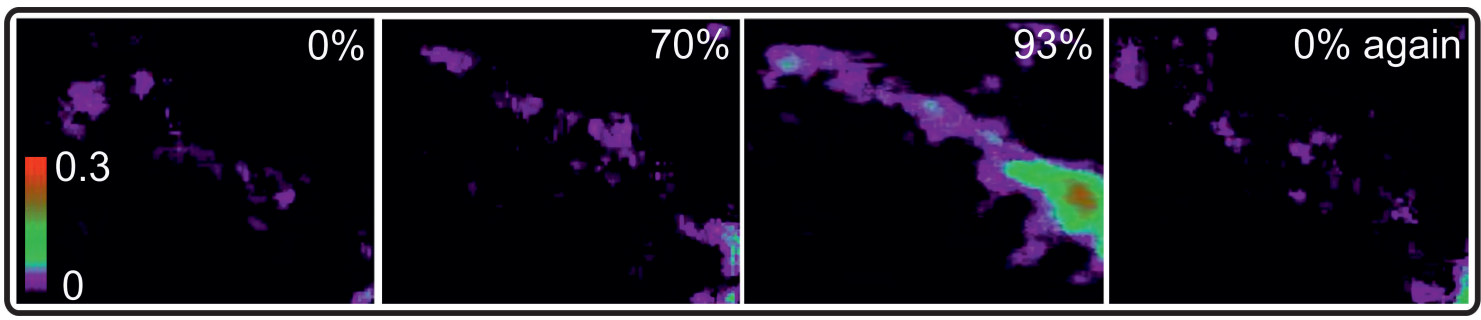

Fig. 9. Series of chemical maps showing the water uptake in aged wood soot particles, the images were measured at $543 \mathrm{eV}$. The images were recorded at the same position at different RH. The color bar represents the scale of the OD in the images.

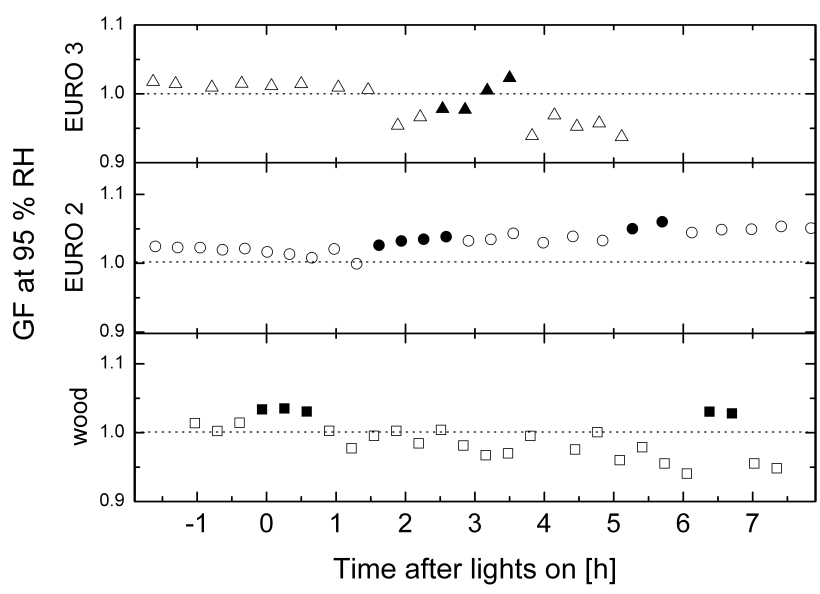

Fig. 10. GF of wood combustion particles and soot particles from the EURO 2 transporter and EURO 3 passenger car measured with an HTDMA. Filled symbols illustrate the GF of $200 \mathrm{~nm}$ sized soot particles with a humidity pre-treatment, which should eliminate further restructuration in the actual growth measurement.

low oxygen content in the particles, the change in optical depth upon increasing humidity is measured against a low background. Therefore, this method allows observing even a small water uptake and independent of whether the particle is compact or agglomerate. In addition, for the case of the aged wood combustion particles, the $\mathrm{O}$ edge spectra discussed above indicate the presence of a liquid aqueous phase.

Figure 11 shows the water uptake in a fresh particle of the EURO 2 transporter. These images were measured at the carbon pre-edge at $0 \%, 80 \%, 90 \%$ and again at $0 \% \mathrm{RH}$. The increase in absorption intensity can be already observed at $80 \%$ with some additional increase in absorption at $90 \%$ RH. After returning the RH to $0 \%$, the absorption intensity was observed in this case to not fully decrease to the initial level. This residual additional absorption could stem from either X-ray radiation damage or residual water trapped in the soot particle due to irreversible transformation of the soot particle during "swelling" (Popovicheva et al., 2008). We find an average water column of $15 \mathrm{~nm}$ in this soot particle at $90 \% \mathrm{RH}$. The particle is calculated to have an average thick- ness of around $55 \mathrm{~nm}$ assuming a density of $1 \mathrm{~cm}^{3} \mathrm{~g}^{-1}$ for the dry carbon backbone. From the 10 investigated particles, 3 particles were found to take up water within the constraints defined above.

The aged soot particles from the EURO 2 transporter were investigated at the pre-edge of the carbon edge and at the oxygen edge. Among 19 investigated particles, water uptake was observed in 12 particles. The aging in the smog chamber thus resulted in a larger fraction of particles with measurable water uptake capability. In the case of the EURO 2 transporter emissions, an increase in particle hygroscopicity was also discernible with the HTDMA, see Fig. 10. As discussed in detail by Tritscher et al. (2011b), the measured growth factor depended on the particle size selected for the measurement. We show here only the case of $200 \mathrm{~nm}$ particles to represent the size range investigated here. In general, the smaller particles $(\leq 100 \mathrm{~nm})$ did not show restructuring but only significant hygroscopic growth. In the larger particles, this hygroscopic growth was buried under the restructuring effect. The restructuring, a collapsing of the fractal soot agglomerate structure under the influence of high humidity, decreases the particle diameter. The fact that humidity driven restructuring occurs indicates the presence of at least hydrophilic material in the agglomerate structure. A GF of 1.02 was measured before processing of the $200 \mathrm{~nm}$ soot particles and a GF of 1.04 was observed after $5 \mathrm{~h}$ of processing (the observed GF increased further to 1.06 with pre-humidification). Again, in $\mathrm{X}$-ray absorption images as those shown, the small amounts of water taken up are detected against a low oxygen background, while the same amount of water leads to only relatively small changes in the mobility diameter for particles of the same size.

Figure 12 shows an example of an unprocessed soot particle from the EURO 3 passenger car. This combustion particle was measured at $0 \%, 85 \%$ and returning to $0 \% \mathrm{RH}$ again. No significant change in X-ray absorbance was observed at any of the three RH levels. In other words, no water uptake was observed in any of the unprocessed EURO 3 passenger car exhaust particles investigated. In half of the aged particles emitted from the passenger car, water associated within the particle was observed at $90 \%$ RH. As discussed in detail by Tritscher et al. (2011b) for the EURO 3 passenger car 


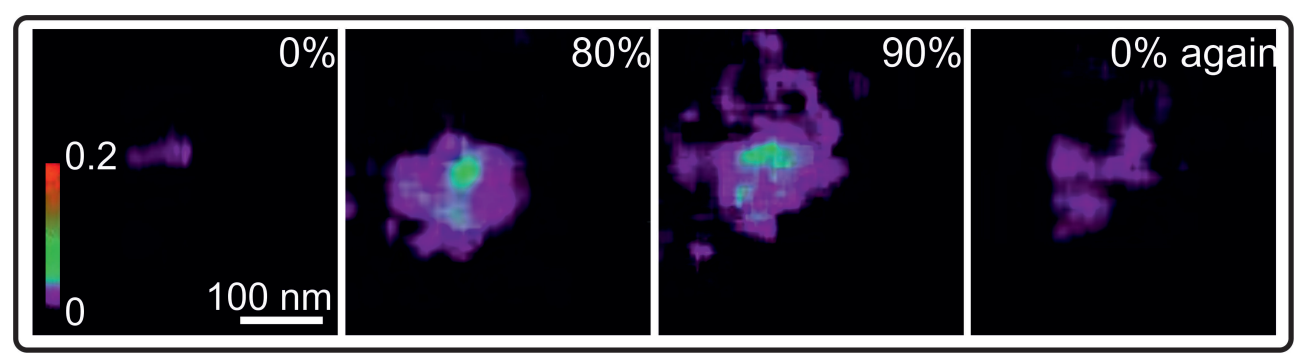

Fig. 11. Absorption maps of an individual unprocessed EURO 2 transporter combustion particle measured at $280 \mathrm{eV}$, at $0,80,90$ and then returning again to $0 \% \mathrm{RH}$.

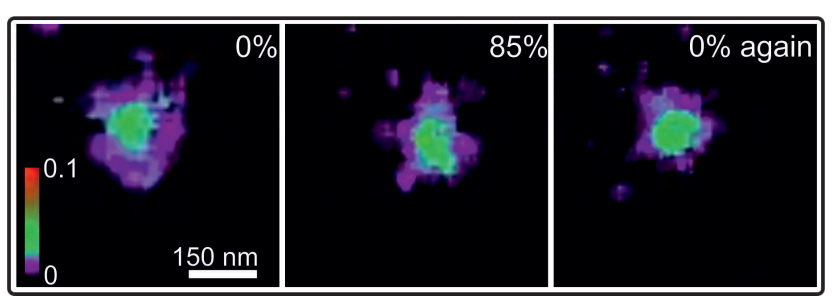

Fig. 12. Absorption maps of a fresh EURO 3 passenger car soot particle measured before the carbon absorption edge at $280 \mathrm{eV}$ at different $\mathrm{RH}$.

emissions, the size effect and the degree of restructuring was even more pronounced than for the corresponding EURO 2 transporter case. While for the $200 \mathrm{~nm}$ particles selected for display here hardly any increase in GF was discernible even after humidity pretreatment, the GF for $100 \mathrm{~nm}$ particles was reached 1.10. Therefore, also for this case X-ray absorption images via their selectivity for oxygen allow retrieving information on low amounts of water uptake in larger agglomerate particles that would not lead to a diameter change detectable by other methods.

It is essential to understand the physical and chemical properties of soot particles in order to model their influence on the climate. The important physical properties include size, morphology and hygroscopic properties of the soot particles. With respect to size, an increase of the mean particle size from $85 \mathrm{~nm}$ to $125 \mathrm{~nm}$ such as observed in the processing of wood combustion particles, could increase the single scattering albedo by about $50 \%$ (Moffet and Prather, 2009). The calculated fractal dimensions of the soot particles indicate that their morphology did not change significantly. One reason might be that a larger amount of hygroscopic compounds would be needed to be condensed on the particles to induce more substantial collapsing already at the low relative humidity of $50 \%$ in the smog chamber (Mikhailov et al., 2006). However, the influence of the water taken up by the soot particles on the scattering and absorption behavior is substantial, too. For example, the absorption coefficient of the wood combustion particle shown in Fig. 9 having $40 \mathrm{~nm}$ water uptake would approximately increase by almost a factor of 1.3
(Mikhailov et al., 2006). A detailed analysis of the morphology of such complex particles and its impact on optical properties is clearly beyond the scope of this work. A more representative number of samples should be investigated and should also be backed up with authentic atmospheric samples as the smog chamber experiments only simulate atmospheric aging with significant limitations. However the present study demonstrates the potential of the STXM technique for this purpose. Further improving spatial resolution without loosing the chemical information may be an important step forward.

\section{Conclusions}

Single particle analysis was performed on fresh and aged wood combustion and diesel exhaust particles using scanning transmission X-ray spectro-microscopy at the carbon and oxygen K-edges, and SEM analysis. The use of a custom reactor cell allowed in-situ exposure to varying relative humidity environments and hence the analysis of water uptake behavior in single particles. Two different cars, a EURO 2 transporter and a EURO 3 passenger car, as well as a wood stove were chosen as combustion sources. Aging of the particles was performed in a smog chamber. Analysis of the particle morphology reveals that all particles increased in size upon photochemical aging, without changes in fractal dimension. Using NEXAFS spectroscopy, we found that in wood combustion particles the carbon functional groups of fresh particles and oxidized compounds that condensed on the soot particles during photochemical aging are very similar, with only slightly increased carboxyl, -alkyl or O-alkyl,and less carbonyl-C content. The mass of the aged particles was dominated by secondary organic material. The minor change in oxidation state may be related to the relatively mild oxidation conditions. Aging of the particles from the EURO 2 transporter led to a substantial increase in carboxyl carbon and smaller increases in unsaturated carbon and phenols. In this case the mass was dominated by secondary organic material and the changes in oxidation state were largely due to condensation of more oxidized secondary material. Particle phase processes may also have played a role. The EURO 
3 passenger car particles revealed much smaller changes in the spectra upon photochemical aging. Since the mass of the aged particles was only slightly above that of the primary particles, it is likely that also oxidation of primary soot contributed to the increase in carboxyl carbon in this case.

Furthermore, we showed that the water uptake behavior changed upon processing. We found that after aging the fraction of particles taking up water increased for all three types of combustion particles. Due to the selectivity of NEXAFS for oxygen, this method allows observing water uptake in amounts that are close to the detection limits for the HTDMA method, especially in conjunction with agglomerated particles. The fact that we have observed water uptake into the interior of the agglomerated particles is consistent with HTDMA growth factor measurements on smaller particles from the same experiments (Tritscher et al., 2011b).

Therefore, the increased amount of carboxyls/phenols stemming either from direct oxidation of the soot particles or from condensation of oxidized organic compounds on the soot particles lead to a higher water uptake ability of the particles. While especially for the larger particles this water uptake leads to only minor size changes, the more hygroscopic character of these particles has likely implications for their $\mathrm{CCN}$ ability. It was not the aim of this study to assess the effect of exhaust aftertreatment systems on the character of aged exhaust aerosol. This is discussed in detail by Chirico et al. (2010) and Tritscher et al. (2011b) based on a larger data set and more experiments than showcased here. Therefore, the conclusions from the present study remain of course limited within the constraints of the samples, the low fuel sulfur content and the specific oxidation conditions used.

Acknowledgements. The SEM measurements were performed in the Laboratory for Mikro- und Nanotechnology at the PSI, especially Anja Weber is acknowledged. The NEXAFS measurements were performed at the Swiss Light Source (SLS), Paul Scherrer Institut, Switzerland. The PolLux end station was financed by the Deutsches Ministerium für Bildung und Forschung (BMBF), contract $05 \mathrm{KS} 4 \mathrm{WE} 1 / 6$ was financed by the Deutsches Ministerium fr Bildung und Forschung (BMBF), contract $05 \mathrm{KS} 4 \mathrm{WE} 1 / 6$, and we appreciate the support of R. Fink for the gas flow system used to operate the microreactor. This work was supported by the Competence Center Energy and Mobility (CCEM) through the project NEADS. We thank M. Birrer for technical support and Lisa Pfaffenberger for insightful discussions. We also thank the Federal Offices for Environment and Energy as well as the project Imbalance within the Competence Center Environment and Sustainability (CCES) for the support of the wood combustion related research.

Edited by: H. Saathoff

\section{References}

Abel, S. J., Haywood, J. M., Highwood, E. J., Li, J., and Buseck, P. R.: Evolution of biomass burning aerosol properties from an agricultural fire in southern Africa, Geophys. Res. Lett., 30, 1783, doi:10.1029/2003GL017342, 2003.

Adachi, K., Chung, S. H., Friedrich, H., and Buseck, P. R.: Fractal parameters of individual soot particles determined using electron tomography: Implications for optical properties, J. Geophys. Res.-Atmos., 112, D14202, doi:10.1029/2006JD008296, 2007.

Adachi, K., Chung, S. H., and Buseck, P. R.: Shapes of soot aerosol particles and implications for their effects on climate, J. Geophys. Res., 115, D15206, doi:10.1029/2009JD012868, 2010.

Alfarra, M. R., Prévôt, A. S. H., Szidat, S., Sandradewi, J., Weimer, S., Lanz, V. A., Schreiber, D., Mohr, M., and Baltensperger, U.: Identification of the mass spectral signature of organic aerosols from wood burning emissions, Environ. Sci. Technol., 41, 5770 5777, 2007.

Cavalleri, M., Ogasawara, H., Pettersson, L. G. M., and Nilsson, A.: The interpretation of X-ray absorption spectra of water and ice, Chem. Phys. Lett., 364, 363-370, 2002.

Chantler, C. T.: Theoretical Form-Factor, Attenuation and Scattering Tabulation for $Z=1-92$ from from $E=1 \mathrm{eV}$ to $\mathrm{E}=0.4-1.0 \mathrm{MeV}$, J. Phys. Chem. Ref. Data, 24, 71-591, 1995.

Chirico, R., DeCarlo, P. F., Heringa, M. F., Tritscher, T., Richter, R., Prévôt, A. S. H., Dommen, J., Weingartner, E., Wehrle, G., Gysel, M., Laborde, M., and Baltensperger, U.: Impact of aftertreatment devices on primary emissions and secondary organic aerosol formation potential from in-use diesel vehicles: results from smog chamber experiments, Atmos. Chem. Phys., 10, 11545-11563, doi:10.5194/acp-10-11545-2010, 2010.

Cocker, D. R., Mader, B. T., Kalberer, M., Flagan, R. C., and Seinfeld, J. H.: The effect of water on gas-particle partitioning of secondary organic aerosol: II. m-xylene and 1,3,5-trimethylbenzene photooxidation systems, Atmos. Environ., 35, 6073-6085, 2001.

DeCarlo, P. F., Kimmel, J. R., Trimborn, A., Northway, M. J., Jayne, J. T., Aiken, A. C., Gonin, M., Fuhrer, K., Horvath, T., Docherty, K. S., Worsnop, D. R., and Jimenez, J. L.: Field-deployable, high-resolution, time-of-flight aerosol mass spectrometer, Anal. Chem., 78, 8281-8289, 2006.

Dhez, O., Ade, H., and Urquhart, S. G.: Calibrated NEXAFS spectra of some common polymers, J. Electron. Spectrosc. Relat. Phenom., 128, 85-96, 2003.

di Stasio, S. and Braun, A.: Comparative NEXAFS study on soot obtained from an ethylene/air flame, a diesel engine, and graphite, Energy Fuels, 20, 187-194, 2006.

Diaz, J., Monteiro, O. R., and Hussain, Z.: Structure of amorphous carbon from near-edge and extended $\mathrm{x}$ ray absorption spectroscopy, Phys. Rev. B, 76, 094201, doi:10.1103/PhysRevB.76.094201, 2007.

Duplissy, J., DeCarlo, P. F., Dommen, J., Alfarra, M. R., Metzger, A., Barmpadimos, I., Prevot, A. S. H., Weingartner, E., Tritscher, T., Gysel, M., Aiken, A. C., Jimenez, J. L., Canagaratna, M. R., Worsnop, D. R., Collins, D. R., Tomlinson, J., and Baltensperger, U.: Relating hygroscopicity and composition of organic aerosol particulate matter, Atmos. Chem. Phys., 11, 1155-1165, doi:10.5194/acp-11-1155-2011, 2011.

Fine, P. M., Cass, G. R., and Simoneit, B. R. T.: Chemical characterization of fine particle emissions from fireplace combustion of woods grown in the northeastern United States, Environ. Sci. 
Technol., 35, 2665-2675, 2001.

Grieshop, A. P., Logue, J. M., Donahue, N. M., and Robinson, A. L.: Laboratory investigation of photochemical oxidation of organic aerosol from wood fires 1: measurement and simulation of organic aerosol evolution, Atmos. Chem. Phys., 9, 1263-1277, doi:10.5194/acp-9-1263-2009, 2009.

Hamilton, J. F., Webb, P. J., Lewis, A. C., Hopkins, J. R., Smith, S., and Davy, P.: Partially oxidised organic components in urban aerosol using GCXGC-TOF/MS, Atmos. Chem. Phys., 4, 12791290, doi:10.5194/acp-4-1279-2004, 2004.

Heringa, M. F., DeCarlo, P. F., Chirico, R., Tritscher, T., Dommen, J., Weingartner, E., Richter, R., Wehrle, G., Prévôt, A. S. H., and Baltensperger, U.: Investigations of primary and secondary particulate matter of different wood combustion appliances with a high-resolution time-of-flight aerosol mass spectrometer, Atmos. Chem. Phys., 11, 5945-5957, doi:10.5194/acp-11-59452011, 2011.

Hitchcock, A.: Analysis of X-ray Images and Spectra, 2006.

Hopkins, R., Tivanski, A. V., Marten, B. D., and Gilles, M. K.: Chemical bonding and structure of black carbon reference materials and individual carbonaceous atmospheric aerosol, J. Aerosol Sci., 38, 573-591, 2007.

Huthwelker, T., Zelenay, V., Birrer, M., Krepelova, A., Raabe, J., Tzvetkov, G., Vernooij, M. G. C., and Ammann, M.: An in situ cell to study phase transitions in individual aerosol particles on a substrate using scanning transmission $\mathrm{x}$-ray microspectroscopy, Rev. Sci. Instrum., 81, 113706-113709, 2010.

Jacobsen, C., Wirick, S., Flynn, G., and Zimba, C.: Soft X-ray spectroscopy from image sequences with sub-100 nm spatial resolution, Journal of Microscopy-Oxford, 197, 173-184, 2000.

Jacobson, M. Z.: Strong radiative heating due to the mixing state of black carbon in atmospheric aerosols, Nature, 409, 695-697, 2001.

Johnson, K. S., Zuberi, B., Molina, L. T., Molina, M. J., Iedema, M. J., Cowin, J. P., Gaspar, D. J., Wang, C., and Laskin, A.: Processing of soot in an urban environment: case study from the Mexico City Metropolitan Area, Atmos. Chem. Phys., 5, 30333043, doi:10.5194/acp-5-3033-2005, 2005.

Kis, V. K., Pósfai, M., and Lábár, J. L.: Nanostructure of atmospheric soot particles, Atmos. Environ., 40, 5533-5542, 2006.

Kocbach, A., Johansen, B. V., Schwarze, P. E., and Namork, E.: Analytical electron microscopy of combustion particles: a comparison of vehicle exhaust and residential wood smoke, Sci. Total Environ., 346, 231-243, 2005.

$\mathrm{Ku}$, B. K. and Maynard, A. D.: Comparing aerosol surfacearea measurements of monodisperse ultrafine silver agglomerates by mobility analysis, transmission electron microscopy and diffusion charging, J. Aerosol Sci., 36, 1108-1124, doi:10.1016/j.jaerosci.2004.12.003, 2005.

McDonald, J. D., Zielinska, B., Fujita, E. M., Sagebiel, J. C., Chow, J. C., and Watson, J. G.: Fine particle and gaseous emission rates from residential wood combustion, Environ. Sci. Technol., 34, 2080-2091, 2000.

Merkus, H.: Particle Size Measurements: Fundamentals, Practice, Quality, Springer, Dodrecht, 2009.

Mikhailov, E., Vlasenko, S. S., Podgorny, I. A., Ramanathan, V., and Corrigan, C. E.: Optical properties of sootwater drop agglomerates: An experimental study, J. Geophys. Res, 111, D07209, doi:10.1029/2005JD006389, 2006.
Moffet, R. C. and Prather, K. A.: In-situ measurements of the mixing state and optical properties of soot with implications for radiative forcing estimates, Proc. Nat. Acad. Sci., 106, 1187211877, 2009.

Nozière, B., Dziedzic, P., and Córdova, A.: Inorganic ammonium salts and carbonate salts are efficient catalysts for aldol condensation in atmospheric aerosols, Phys. Chem. Chem. Phys., 12, 3864-3872, 2010.

Outka, D. A. and Stohr, J.: Curve Fitting Analysis of nearEdge Core Excitation-Spectra of Free, Adsorbed, and Polymeric Molecules, J. Chem. Phys., 88, 3539-3554, 1988.

Paulsen, D., Dommen, J., Kalberer, M., Prévôt, A. S. H., Richter, R., Sax, M., Steinbacher, M., Weingartner, E., and Baltensperger, U.: Secondary organic aerosol formation by irradiation of 1,3,5trimethylbenzene- $\mathrm{NO}_{\mathrm{x}}-\mathrm{H}_{2} \mathrm{O}$ in a new reaction chamber for atmospheric chemistry and physics, Environ. Sci. Technol., 39, 2668-2678, 2005.

Petters, M. D., Prenni, A. J., Kreidenweis, S. M., DeMott, P. J., Matsunaga, A., Lim, Y. B., and Ziemann, P. J.: Chemical aging and the hydrophobic-to-hydrophilic conversion of carbonaceous aerosol, Geophys. Res. Lett., 33, L24806, doi:10.1029/2006GL027249, 2006.

Popovicheva, O., Persiantseva, N. M., Shonija, N. K., DeMott, P., Koehler, K., Petters, M., Kreidenweis, S., Tishkova, V., Demirdjian, B., and Suzanne, J.: Water interaction with hydrophobic and hydrophilic soot particles, Phys. Chem. Chem. Phys., 10, 23322344, 2008.

Raabe, J., Tzvetkov, G., Flechsig, U., Boge, M., Jaggi, A., Sarafimov, B., Vernooij, M. G. C., Huthwelker, T., Ade, H., Kilcoyne, D., Tyliszczak, T., Fink, R. H., and Quitmann, C.: PolLux: A new facility for soft x-ray spectromicroscopy at the Swiss Light Source, Rev. Sci. Instrum., 79, 113704-113710, 2008.

Renard, J. B., Ovarlez, J., Berthet, G., Fussen, D., Vanhellemont, F., Brogniez, C., Hadamcik, E., Chartier, M., and Ovarlez, H.: Optical and physical properties of stratospheric aerosols from balloon measurements in the visible and near-infrared domains. III. Presence of aerosols in the middle stratosphere, Appl. Opt., 44, 4086-4095, 2005.

Robinson, A. L., Donahue, N. M., Shrivastava, M. K., Weitkamp, E. A., Sage, A. M., Grieshop, A. P., Lane, T. E., Pierce, J. R., and Pandis, S. N.: Rethinking organic aerosols: Semivolatile emissions and photochemical aging, Science, 315, 1259-1262, 2007.

Russell, L. M., Maria, S. F., and Myneni, S. C. B.: Mapping organic coatings on atmospheric particles, Geophys. Res. Lett., 29, L1779, doi:10.1029/2002GL014874, 2002.

Saathoff, H., Naumann, K. H., Schnaiter, M., Schock, W., Mohler, O., Schurath, U., Weingartner, E., Gysel, M., and Baltensperger, U.: Coating of soot and $\left(\mathrm{NH}_{4}\right)(2) \mathrm{SO}_{4}$ particles by ozonolysis products of alpha-pinene, J. Aerosol Sci., 34, 1297-1321, 2003.

Sage, A. M., Weitkamp, E. A., Robinson, A. L., and Donahue, N. M.: Evolving mass spectra of the oxidized component of organic aerosol: results from aerosol mass spectrometer analyses of aged diesel emissions, Atmos. Chem. Phys., 8, 1139-1152, doi:10.5194/acp-8-1139-2008, 2008.

Schwarz, J. P., Spackman, J. R., Fahey, D. W., Gao, R. S., Lohmann, U., Stier, P., Watts, L. A., Thomson, D. S., Lack, D. A., Pfister, L., Mahoney, M. J., Baumgardner, D., Wilson, J. C., and Reeves, J. M.: Coatings and their enhancement of black carbon light absorption in the tropical atmosphere, J. Geophys. Res.-Atmos., 
113, D03203, doi:10.1029/2007JD009042, 2008.

Tritscher, T., Dommen, J., DeCarlo, P. F., Gysel, M., Barmet, P. B., Praplan, A. P., Weingartner, E., Prévôt, A. S. H., Riipinen, I., Donahue, N. M., and Baltensperger, U.: Volatility and hygroscopicity of aging secondary organic aerosol in a smog chamber, Atmos. Chem. Phys., 11, 11477-11496, doi:10.5194/acp11-11477-2011, 2011a.

Tritscher, T., Jurányi, Z., Martin, M., Chirico, R., Gysel, M., Heringa, M. F., DeCarlo, P. F., Sierau, B., Prévôt, A. S. H., Weingartner, E., and Baltensperger, U.: Changes of hygroscopicity and morphology during ageing of diesel soot, Environ. Res. Lett., 6, 034026, doi:10.1088/1748-9326/6/3/034026, $2011 \mathrm{~b}$.

Tzvetkov, G., Graf, B., Fernandes, P., Fery, A., Cavalieri, F., Paradossi, G., and Fink, R. H.: In situ characterization of gas-filled microballoons using soft X-ray microspectroscopy, Soft Matter, 4, 510-514, 2008.

van Poppel, L. H., Friedrich, H., Spinsby, J., Chung, S. H., Seinfeld, J. H., and Buseck, P. R.: Electron tomography of nanoparticle clusters: Implications for atmospheric lifetimes and radiative forcing of soot, Geophys. Res. Lett., 32, L24811, doi:10.1029/2005GL024461, 2005.

Vernooij, M. G. C., Mohr, M., Tzvetkov, G., Zelenay, V., Huthwelker, T., Kaegi, R., Gehrig, R., and Grobety, B.: On source identification and alteration of single diesel and wood smoke soot particles in the atmosphere; an X-Ray microspectroscopy study, Environ. Sci. Technol., 43, 5339-5344, 2009.

Weingartner, E., Baltensperger, U., and Burtscher, H.: Growth and structural change of combustion aerosols at high relative humidity, Environ. Sci. Technol., 29, 2982-2986, 1995.

Weingartner, E., Burtscher, H., and Baltensperger, U.: Hygroscopic properties of carbon and diesel soot particles, Atmos. Environ., 31, 2311-2327, 1997.
Weitkamp, E. A., Sage, A. M., Pierce, J. R., Donahue, N. M., and Robinson, A. L.: Organic aerosol formation from photochemical oxidation of diesel exhaust in a smog chamber, Environ. Sci. Technol., 41, 6969-6975, doi:10.1021/es070193r, 2007.

Wernet, P., Nordlund, D., Bergmann, U., Cavalleri, M., Odelius, M., Ogasawara, H., Naslund, L. A., Hirsch, T. K., Ojamae, L., Glatzel, P., Pettersson, L. G. M., and Nilsson, A.: The structure of the first coordination shell in liquid water, Science, 304, 995999, 2004.

Worringen, A., Ebert, M., Trautmann, T., Weinbruch, S., and Helas, G.: Optical properties of internally mixed ammonium sulfate and soot particles-a study of individual aerosol particles and ambient aerosol populations, Appl. Opt., 47, 3835-3845, 2008.

Xue, H. X., Khalizov, A. F., Wang, L., Zheng, J., and Zhang, R. Y.: Effects of dicarboxylic acid coating on the optical properties of soot, Phys. Chem. Chem. Phys., 11, 7869-7875, 2009.

Zelenay, V., Ammann, M., Krepelov, A., Birrer, M., Tzvetkov, G., Vernooij, M. G. C., Raabe, J., and Huthwelker, T.: Direct observation of water uptake and release in individual submicrometer sized ammonium sulfate and ammonium sulfate/adipic acid particles using X-ray microspectroscopy, J. Aerosol Sci., 42, 38-51, doi:10.1016/j.jaerosci.2010.11.001, 2011a.

Zelenay, V., Monge, M. E., D’Anna, B., George, C., Styler, S., Huthwelker, T., and Ammann, M.: Increased steady state uptake of ozone on soot due to UV/Vis radiation, J. Geophys. Res., 116, D11301, doi:10.1029/2010JD015500, 2011b.

Zhang, R. Y., Khalizov, A. F., Pagels, J., Zhang, D., Xue, H. X., and McMurry, P. H.: Variability in morphology, hygroscopicity, and optical properties of soot aerosols during atmospheric processing, P. Natl. Acad. Sci., 105, 10291-10296, 2008. 